\title{
Low Power Considerations and Timing Simulation Analysis of Recent 8-Bit Embedded Controllers including AT89C5130A/31A-M-Frozen-in-Idle-State MCUs for WSN Applications
}

\author{
Seema Ajay Agarkar \\ M.E. Research Scholar \\ STM Nagpur Uni. Nagpur, India
}

\author{
Dr.K.D.Kulat \\ Professor and Head (EC) \\ VNIT, Nagpur, India
}

\author{
Dr. R.V.Kshirsagar \\ Professor (EC) and Dean \\ PCEA, Nagpur, India
}

\begin{abstract}
This is an era of SOC (System-on-Chip) based computing. Embedded systems play significant role in representing computing power in the smallest possible device that too in the most liberal way. Microcontroller is represented as a major embedded system product and is responsible to carry computing power on any-timeany-where basis. The modern PC or PC-based industrial applications use many small microcontroller circuits in keyboards, printers, modems, disk controller, sound card, CD-ROM drive, mouse, bar-code reader (printing industries), power drill machines (automobile industries), SCADA system (process industries), fire alarm system (security and safety engineering) and smart cards (banking industry) to name a few. Microcontroller makes it possible to empower the simplest application and the product with computing intelligence at an affordable cost. The selection of the microcontroller is based on the facts, such as, availability of software development aids, market trend and design expertise, power consumption and computing speed, instruction set and on chip memory, prototype size and design, I/O and timer availability, possibilities of an application specific integrated circuit (ASIC) based implementation and upward compatibility.

This paper deals with detailed comparative study of the features of the recent 8-bit microcontrollers available till December 2010 from leading manufacturers and the timing simulation analysis of some useful microcontrollers. The outcome of the comparative study and timing simulation analysis is presented in terms of recommendations readily available to the designers and first generation entrepreneurs to encourage low power and low cost designs, particularity for precision agriculture and WSN based applications. In the developing countries, such as in India, electronics hardware production increased from Rs. 50,500 crore in 2004-05 to Rs. 97,260 crore in 2008-09, with a cumulative annual growth rate of $17.3 \%$. The production of electronics hardware in India has grown from Rs. 97,260 crore in 2008-09 to Rs. 109,940 crore in 2009-10, registering a growth of $13 \%$, slightly low due to global slowdown [10]. The control, instrumentation and industrial sector of electronics industry use critical hardware technologies and systems with built-in software. Low cost and low power microcontroller based system design can play a significant role to increase employability and the export in this sector, particularly, in the developing country.
\end{abstract}

\section{General Terms}

Timing Simulation Analysis, Embedded Controllers, Low Cost Embedded Solution, ASIC

\section{Keywords}

Microcontroller, PIC, Atmel, Wireless Sensor Network, Low Power Device, Pico Power Technology

\section{INTRODUCTION}

The information revolution is happening all around the human being through the extensive use of laptops, cellular phones, videoconferencing, and the Internet. The last 50 years in information processing have shown a relentless drive towards distributed intelligence. From the mainframe computers of the 1950 s to the minicomputers of the 1970 s to the desktop PCs of the 1980 s and to the laptops of the 1990 s, the highly visible drive towards distributed intelligence has been made possible by the continually improving performance of semiconductors, particularly microprocessors.

The embedded information processing revolution is truly hidden inside the products which are used every day. For example, a washing machine adjusting the height of the water based on the load size, a car security system restricting an authorized entry and unlocking the doors when driver approaches the car or a home lighting system saving the power by adjusting the light intensity as per ambient light.

All these examples are of information processing, or intelligence, inside a product. This kind of intelligence is abundant in all kind of products and appliances. Even toys can have more computing power than medium-size computers had 35 years ago. This is embedded information processing revolution. The main driving force behind this information is the constant evolution since last 40 years in chip manufacturing and fairly high levels of computing power at the least price. The result is that number of applications with innumerable and previously unforeseen opportunities for distributed embedded intelligence.

Worldwide, especially in the developed countries, such intelligence is found in five broad markets with a high level of penetration. The first is the consumer market, which includes home appliances and entertainment equipment. The second is automotive sector, where a modern car has nearly 50-100 microcontrollers providing intelligence and control to control precisely various parameters including the speed of the auto powered window, instant working of an air bag in case of an emergency, keyless entry and antilock braking. The third market is office automation, which includes PCs, keyboards, copiers and printers. The fourth market, telecommunications, includes cellular phones, pagers and answering machines. The fifth market includes industrial product, such as door locks in hotel rooms, automatic taps and industrial machinery. 
The revolution in embedded intelligence is driven by microcontrollers. Most microcontrollers contain a number of hardware modules. Earlier, many of these were designed as separate chips in a conventional microprocessor system. Integrating them into a single microcontroller chip allows for greater functionality in a single chip and saves space. Due this advantage of embedded intelligence revolution, more than 30 times as many microcontrollers each year or nearly 2.5 billion units, compared with about 75 million microprocessors are consumed each year in the desktop PC-based information revolution.

Today, an average business person uses one microprocessor in the laptop but 12 to 14 microcontrollers are used by everyone, every day, knowingly or unknowingly, in mobile phones, pager, digital clock, pocket recorder and calculator. Microcontrollers are in a laptop computer's mouse, keyboard, modem, fax card, sound card, and battery charger. Since, last 10 years, most of the builders in metro cities have started providing homes and now smart homes, wherein microcontrollers are found almost in every gadget including "movement-sensor" based illumination, door locks, alarm clocks, thermostat, air conditioner and home security systems. Microcontrollers are available in TV remote, hair dryer, $\mathrm{CD}$ player and refrigerators. Hence, microcontrollers are found at every place, including homes, offices, and automobiles. New embedded and intelligent processors like 8-bit PIC controllers such as PIC16F193X family of microcontrollers (MCUs) featuring Microchip's enhanced Mid-range 8-bit core-the PIC16F1934, PIC16LF1934, PIC16F1936, PIC16LF1936, PIC16F1937 and PIC16LF1937, announced recently in July 2009, are widely applicable in wireless sensor networks due to their intelligent features and very low power requirements in the range of a few nano-watts [14]. It is estimated that it will further reduce the price of the sensor network and hence the WSN system will become cost effective thus easily employable in many commercial and non-commercial applications [3], [4].

Although 4-bit microcontrollers are relatively inexpensive, typically costing under $\$ 1.00$ each, they generally lack the minimum performance and features required by today's design engineers for product differentiation and are typically used only to produce basic functionality in products. 16-bit and 32-bit architectures provide very high performance; they can be expensive for most high-volume embedded control applications, typically costing $\$ 6.00$ to $\$ 12.00$ each. As a result, manufacturers of competitive, high-volume products have increasingly found 8bit microcontrollers, which typically cost $\$ 1.00$ to $\$ 8.00$ each, to be the most cost-effective embedded control solution [14] , [15] . Today, there is an explosion in the applications of microcontrollers and they are expected to deliver embedded intelligence. Almost every end product, if there is electrical power applied to it, uses microcontroller. However, in most of the developing countries, "microcontroller based office automation and entertainment products" are in use. The scope for deeper penetration of microcontroller based products in other walks of life is yet to be fully established due to one or several reasons listed below,

\subsection{Socio-economic reasons}

- Poor economic status of the population in most of the developing countries does not permit to use these products.

- Lack of awareness about technology and fear factor of the modern technology are important reasons.
- Less accessibility to these products in the local market is also the reason why people do not buy these products who can afford it.

\subsection{Technical reasons}

- Design expertise and maintenance facilities are not easily available.

- Programming and reprogramming extension centers are very rare.

- Literature and guidelines for indigenous product development are not available.

- Detailed guideline for the selection of microcontroller for specific application is not available.

- Analytical and simulation case studies for indigenous product development are not available.

- Most of the products are imported and hence the buying cost is high, even though the cost of microcontroller IC is less and affordable.

- Design and development of microcontroller based system is limited to research projects only and not converted into the useful product.

- Low cost product development using microcontroller is not emphasized heavily.

- Microcontroller based product development suitable to national need and for applications such as precision agriculture, wireless sensor network based environmental monitoring and automatic solar tracking is rare and industry sector is not aware about it.

In the subsequent sections, some of these major issues are addressed with the help of detailed comparative study and timing simulation analysis. Study of various initiatives and policies of the Government in the developing countries, especially, in the countries such as India, in this field is useful in the present context.

\section{SCENARIO OF ELECTRONICS INDUSTRIES AND GOVERNMENT POLICIES}

It is necessary to study the policies and new promotional schemes of the Government so that the developmental efforts for indigenous "microcontroller -based -low -power- technologies" get further boost.

\subsection{Electronics Hardware Manufacturing (EHM)}

Production and export of goods, hardware, gadgets and control circuits of electronics, in short, Electronics Hardware Manufacturing (EHM) continues to be a thrust area for the Government of India, as a major revenue earner, in addition to IT sector. The Special Incentive Package Scheme (SIPS) that was announced in 2007 to invite investment proposals for setting up semiconductor fabrication, microcontroller based instrumentation and other micro and nano-technology manufacturing industries in India. SIPS has received a very positive response from the prospective investors with an investment of about Rs. 161,000 crore, over a period of next 10 years. "In- principle" approval has been issued to 13 applications, out of which 5 applications have reported financial closure in excess of Rs. 1,000 crore [10]. 


\subsection{The Technology Incubation and Development of Entrepreneurs (TIDE) scheme} The Department of Electronics and IT (DEIT) of Government of India (GOI) has taken various initiatives towards promotion of technology innovation and commercialization in the field of Electronics \& IT. The Technology Incubation and Development of Entrepreneurs (TIDE) scheme launched to strengthen the technology incubation centers at the institutions of higher learning has been further expanded to cover 12 TIDE centers and 2 virtual incubation centers in addition to already approved 15 TIDE centers. Indian electronics hardware production increased from Rs. 50,500 crore in $2004-05$ to Rs. 97,260 crore in $2008-09$, with a cumulative annual growth rate of $17.3 \%$. The production of electronics hardware in the country is estimated to grow from Rs. 97,260 crore in 2008-09 to Rs. 109,940 crore in 2009-10, registering a growth of $13 \%$, slightly low due to global slowdown [10].

\subsection{Task Force and expected growth}

The demand for electronics hardware is being fuelled by the relatively high growth rate of the Indian economy, aspirations of the younger generation and the large middle class in India with increasing disposable incomes. Thus, there is a big opportunity for stepping up production of electronics hardware in the country. India has the potential to develop and manufacture electronic hardware for the global markets and gain higher global share besides meeting the country's future requirement in the converging areas of information, communication and entertainment.

The Government has identified growth of electronics hardware manufacturing sector as a thrust area and has taken a number of steps on an on-going basis for promotion of this industry in the country. One of the major initiatives taken by the Government is the formation of the "Task Force" to suggest measures to stimulate the growth of "Electronics Hardware Manufacturing Industry" in the country in view of the enormous opportunities ahead and need to sustain the growth of this sector. As per the Report of the Task Force in Dec.2009, the demand for electronics hardware in the country is projected to increase from the present US $\$ 45$ billion in 2009 to US \$ 125 billion by 2014 and US $\$ 400$ billion by 2020 . The electronics hardware production is projected to grow from about US $\$ 20$ billion in 2009 to US $\$ 100$ billion by 2014 and US $\$ 400$ billion by 2020, with exports growing from about US $\$ 4.4$ billion in 2009 to US $\$ 15$ billion by 2014 and US $\$ 80$ billion by 2020 . To bridge the gap of production and supply, the Task Force has suggested several measures for rapid growth of the industry and has defined a roadmap for the industry in the medium term as well as long term. The overall goal is to arrive at a combined vision of Government and Industry so that the electronics hardware production sector should aspire to achieve in next few years, particularly in terms of investment, contribution to GDP and employment. The Department of Electronics and IT is in the process of taking up the recommendations for appropriate implementation on a fast track basis, so that the IT and Electronics Industry in India achieves the targets as envisioned by the Task Force [10].

\subsection{The Export Promotion Capital Goods (EPCG) Scheme}

In tandem to the formation of special task force, Government of India has outward looking and liberal trade policy towards India's economic reforms. As a result, approvals for all foreign direct investment up to $100 \%$ in the electronics hardware-manufacturing sector are under the automatic route. The general Export Promotion Capital Goods (EPCG) Scheme allows import of capital goods for pre-production, production and post-production at 3\% customs duty. However, the Zero duty EPCG Scheme is available to exporters of electronic products. It allows import of capital goods for pre-production, production and post-production at $0 \%$ customs duty [10].

\subsection{Special Economic Zones (SEZs)}

Seven Special Economic Zones (SEZs) are being set up to enable hassle free manufacturing and trading for export purposes. Sales from Domestic Tariff Area to SEZs are being treated as physical export. This entitles domestic suppliers to Drawback/ Duty Entitlement Pass Book (DEPB) benefits, CST exemption and Service Tax exemption. 100\% Income Tax exemption on export profits is available to Special Economic Zone (SEZ) Units for 5 years, $50 \%$ for next 5 years and $50 \%$ of ploughed back profits for 5 years thereafter. Even if the mean rate of excise duty (CENVAT) is $10 \%$, microprocessors, microcontrollers and associated parts, components and accessories are exempted from excise duty. Hard Disc Drives, Floppy Disc Drives, CD ROM Drives, DVD Drives/DVD Writers, Flash Memory and ComboDrives are also exempted from excise duty [10].

\subsection{Production performance till 2009-10}

The production performance of various industry groups in the Electronics hardware and Software \& Services Sector in 2009-10 is shown below in fig. 1 to fig. 6 . The Control, Instrumentation and Industrial Sector of Electronics/IT industry include critical hardware technologies and systems with built-in software. Microcontroller based system design can play a significant role to increase the export in this particular sector. It is a very challenging area which is multidisciplinary in nature requiring high level of technical skill in designing systems for applications in a variety of industrial sectors of the economy. One major sector which may show significant contribution in the production and export under this head is "Microcontroller based Low Cost Precision Electronic Systems" for agricultural and industrial applications. Whereas, in India, a good amount of expertise in conceptualizing such systems and its erection and commissioning is available, the sector is very largely dependent on import of critical hardware and associated software. Large projects are implemented and huge money is invested with total import of designed products from abroad without any knowledge of its design. In most cases, this leads to higher initial cost and a much higher maintenance cost in the long run. This process is continuing for a long time now. The Department of Electronics and IT, through its Industrial Applications Programme is trying to support this sector, by providing proven indigenous technologies wherever possible. Several technologies developed through national collaborative programmes are applied for field demonstration. This includes energy related equipment for improvement of electric power quality, controllers in the area of industrial automation systems, equipment for railway traction, etc. A large collaborative programme on Intelligent Transportation System which includes various technology modules for application in the road transportation sector has also been launched recently. During the year 2009-10, the production of this segment is estimated to be Rs. 13,630 crore, as against Rs. 12,740 crore in the fiscal year 2008-09, registering a growth of about 7 per cent [10]. 


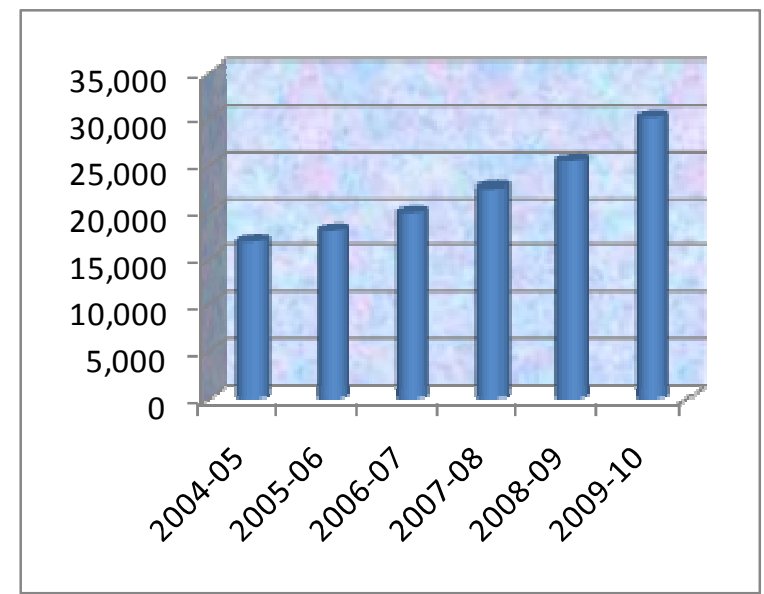

Fig. 1 Consumer Electronics Production in India (Rs. Crore)

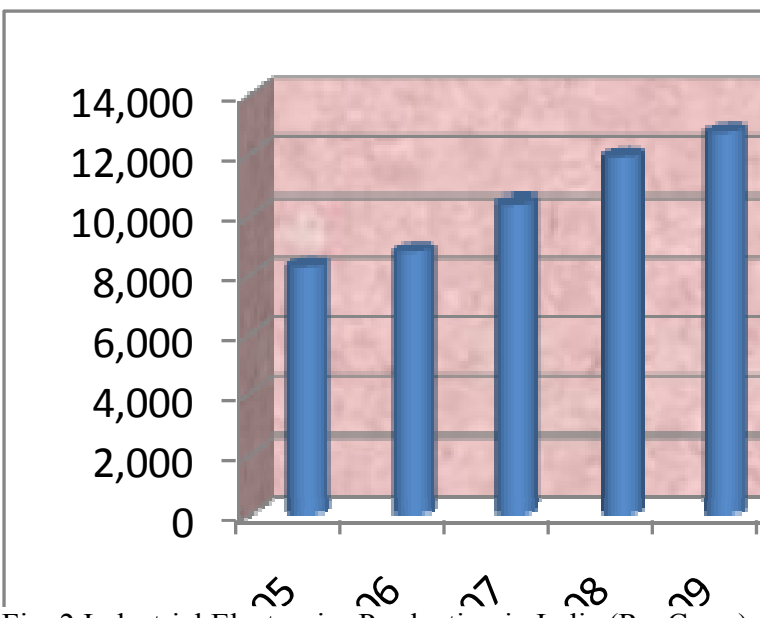

Fig. 2 Industrial Electronics Production in India (Rs. Crore)



Fig. 3 Strategic Electronics Production in India (Rs. Crore)

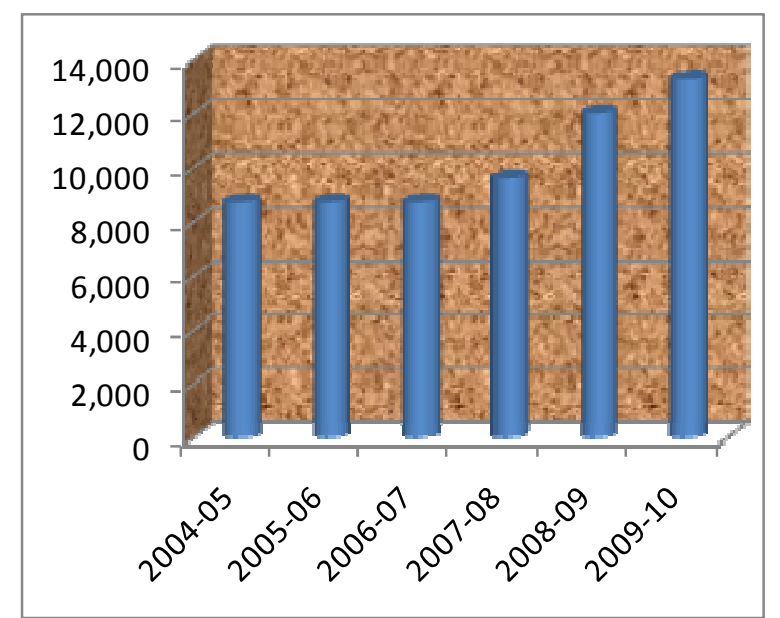

Fig. 4 Electronics Components Production in India (Rs. Crore)

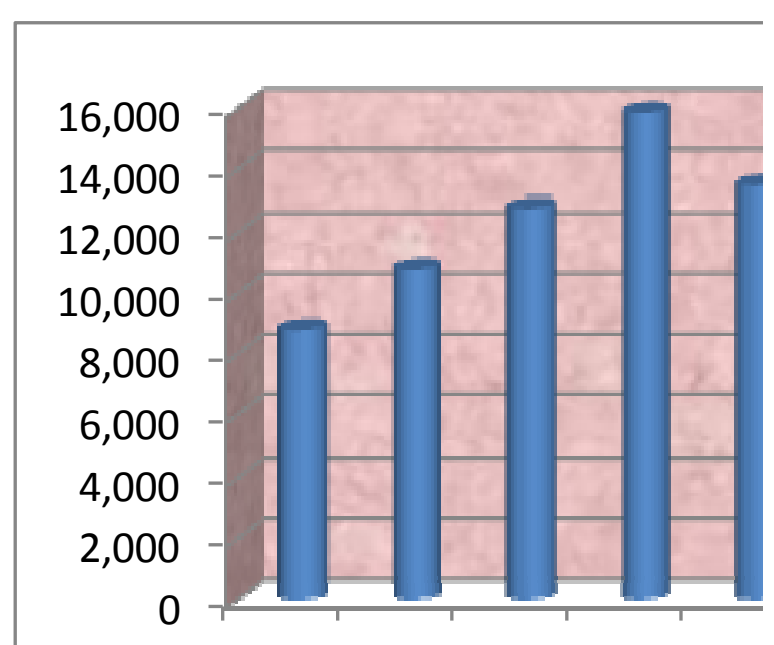

Fig.5 Computer Production in India (Rs. Crore)



Fig. 6 Electronic communication and equipment Production in India (Rs. Crore) 


\subsection{Critical analysis of Indian scenario of electronics industries and Government policies}

- Electronics and IT sector continues to be a major employment provider in the developing country, such as India.

- The rise in consumer electronics production is from Rs. 16,800 crore in the year $2004-05$ to Rs. 30,150 crore in 2009-10 which is almost $179 \%$ in 05 years. The growth of industrial electronics production is from Rs. 8,300 crore to Rs. 13,630 crore which is almost $164 \%$ in 05 years. Strategic electronics production has grown from Rs.3,000 crore in $2004-05$ to Rs.6,980 crore with a rise of $232 \%$ in five years span. Similarly, production of electronics components has increased from Rs. 8,800 crore to Rs. 13,360 crore with a rise of $151 \%$ in five years span ending in 2009-10. Electronic communication and broadcast equipment production has seen a whopping growth of $653 \%$ in five years span (from Rs. 4800 crore in 2004-05 to Rs. 31,390 crore in 2009-10). These figures indicate the ever increasing demand for the products of electronics industry in India.

- Production details related to most of the prominent fields in electronics sector are listed. However, the field of medical electronics is yet to be fully explored in India. For precision medical electronics equipments and instruments, India is dependent on the developed countries. Most of the medical electronic equipments use recent microcontrollers for precision measurement and control.

- Indian entrepreneurs must take benefit of the Government schemes such as EHM, SIPS and TIDE for low cost production and export of microcontroller based products.

- There is a tremendous scope to provide employability in India for electronics engineers being produced every year by the education sector. Development of indigenous electronic hardware and embedded technologies will further restrict the brain drain. In fact, the growing technical institutes in India are the facilitators for the forthcoming embedded system training centers and production houses if the technology incubation policy of Department of Science and technology (DST), Government of India is successfully implemented.

- Microprocessors, microcontrollers and associated parts, components and accessories are exempted from excise duty hence low cost production using microcontrollers is not a dream now.

- The demand for electronics hardware in the country is projected to increase from the present US $\$ 45$ billion in 2009 to US $\$ 125$ billion by 2014 and US $\$ 400$ billion by 2020. The electronics hardware production is projected to grow from about US \$ 20 billion in 2009 to US \$ 100 billion by 2014 and US $\$ 400$ billion by 2020 , with exports growing from about US \$ 4.4 billion in 2009 to US \$ 15 billion by 2014 and US $\$ 80$ billion by 2020 . It seems that there is a large gap between demand and supply of electronics hardware production. Hence, low cost indigenous technologies must be successfully developed.

- Development of indigenous technologies is important so that the production can be immediately taken up. One objective of this research work undertaken by the authors is to develop a low cost technology based on microcontroller.
- The low cost technology is especially targeted for farmers in the developing countries including Indian farmers who are using green houses for higher agricultural yield but cannot buy costly instrumentation for automation.

- The development and maximum commercialization of such technology will give two distinct advantages, such as, increase in the employability and penetration of the recent technology to the masses so that the common man can reap the fruits of it. It is easily possible through embedded revolution due its low cost feature.

\section{SELECTION OF SPECIFIC MICROCONTROLLER}

Selection of a specific microcontroller is based on the facts, such as, availability of software development aids, market trend and design expertise, power need and speed, instruction set and on chip memory, prototype size and design, I/O and timer availability, possibilities of an application specific integrated circuit (ASIC) based implementation and upward compatibility.

\section{IMPORTANT BLOCKS AND THEIR DEFINITIONS}

As seen in fig.7, the important blocks of microcontroller includes mainly reset and brownout detector, analog $\mathrm{I} / \mathrm{O}$ ports and watchdog timer in addition to clock oscillator and real time clock. Clock oscillator executes the program out of the program memory at a certain rate. This rate is determined by the frequency of the clock oscillator. The reset circuit in the controller ensures that at startup all the components and control circuits in the controller start at a predefined initial state and all the required registers are initialized properly. The brownout detector is a circuit that monitors the power supply voltage, and if there is a momentary drop in voltage, resets the processor so that the drop in voltage does not corrupt register and memory contents, which could lead to faulty operation of the controller [14], [15].

Analog input is processed using an analog-to-digital converter (ADC). The controller could be equipped with an integrated ADC or an analog comparator, which is used under software control to perform A-to-D conversion. ADCs are used to acquire sensor data from sensor nodes in WSN and other devices such as temperature sensors and pressure sensors; such sensors often produce proportional analog voltage data. Analog output is available using a digital-to-analog converter (DAC). Most controllers are equipped with pulse-width modulators that can be used to get analog voltage with a suitable external RC filter. DACs are used to drive motors, for visual displays (of the older VU meter types), to generate sound or music, etc.

A watchdog timer (WDT) is a special timer with a specific function. It is usually used to prevent software crashes. Once armed, the WDT increments an internal counter at some rate. If the user program does not reset the counter, the counter overflows, which is used to reset the controller. The user software is programmed suitably, therefore, frequently enough, to reset the WDT to give a sort of "I am alive" indication. The assumption is that if the user program does not reset the WDT, it has failed in some way and therefore rather than a system crash or unpredictable system performance, it is better to reset the system. A real timer clock (RTC) is a special timer with the task of maintaining time of day, date, etc. It can be used to time-stamp events [14], [15]. 
It is clear from fig.7 that microcontroller needs minimum extra components for external interfacing as many important blocks are available on chip. Most of the recent microcontrollers provide on chip A to D conversion facility so that applications like WSN are designed with optimum space and power requirements. Such devices are useful for remote and space applications where the batteries are charged using solar energy. Compatible sensors are directly interfaced with analog I/O port so as to provide low cost and very low cost solutions and thus the third world countries can take benefit of modern technology for applications like weather forecasting, AWACS and Tsunami warning systems to save hundreds and thousands of lives.

\section{IMPORTANT CONSIDERATIONS FOR LOW POWER APPLICATIONS}

\subsection{PIC 8-bit MCUs Family Members}

Table-1 to table -8 show important differences between 8 bit PIC and 8-bit Atmel family members for their proper and optimum utilization in specific industrial applications demanding specific I/O pins, memory size and ADC. For example, PIC16C74A may be demanded in low cost and very low power WSN applications as it has 8 ADC channels and 1 USART. PIC 16C62A is useful in bulk production of electronic toys due to less cost [11], [12], [13], [14], [15].

Table 1: PIC 8- bit Family Member Differences

\begin{tabular}{|c|c|c|c|c|c|c|c|}
\hline 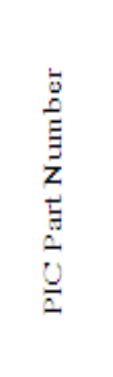 & 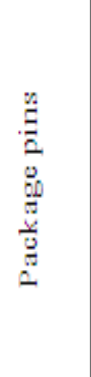 & $\frac{n}{3}$ & $\begin{array}{l}\sum \\
\frac{2}{2} \\
\frac{1}{9}\end{array}$ & $\begin{array}{l}n \\
2 \\
2 \\
2\end{array}$ & $\begin{array}{l}\frac{n}{0} \\
0 \\
0 \\
0 \\
0 \\
0 \\
0 \\
0 \\
0 \\
0 \\
0 \\
0 \\
0 \\
0\end{array}$ & $\begin{array}{l}\bar{\alpha} \\
\frac{1}{\sigma} \\
\frac{\omega}{b}\end{array}$ & 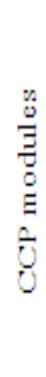 \\
\hline $16 \mathrm{C} 62 \mathrm{~A}$ & 28 & 22 & $2 \mathrm{~K}$ & 128 & 0 & 0 & 1 \\
\hline $16 \mathrm{C} 63$ & 28 & 22 & $4 \mathrm{~K}$ & 192 & 0 & 1 & 2 \\
\hline $16 \mathrm{C} 64 \mathrm{~A}$ & $40 / 44$ & 33 & $2 \mathrm{~K}$ & 128 & 0 & 0 & 1 \\
\hline $16 \mathrm{C} 65 \mathrm{~A}$ & $40 / 44$ & 33 & $4 \mathrm{~K}$ & 192 & 0 & 1 & 2 \\
\hline $16 \mathrm{C} 72$ & 28 & 22 & $2 \mathrm{~K}$ & 128 & 5 & 0 & 1 \\
\hline $16 \mathrm{C} 73 \mathrm{~A}$ & 28 & 22 & $4 \mathrm{~K}$ & 192 & 5 & 1 & 2 \\
\hline $16 \mathrm{C} 74 \mathrm{~A}$ & $40 / 44$ & 33 & $4 \mathrm{~K}$ & 192 & 8 & 1 & 2 \\
\hline
\end{tabular}



Fig. 7 Microcontroller based external interfacing

Table 2: Atmel 8-bit Flash ISP - Single Cycle Core Family Members

\begin{tabular}{|c|c|c|}
\hline S.N. & Device & Description \\
\hline 1 & 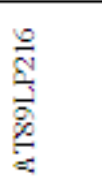 & $\begin{array}{c}\text { 2-Kbyte In-system Programmable Flash, } \\
\text { Single Cycle } 8051 \text { Microcontroller, } 128 \\
\text { Bytes RAM, PWM, UART, SPI, I/O = 16, } \\
\text { Analog Comparator, Internal RC Oscillator, } \\
\text { On-chip Debug }\end{array}$ \\
\hline 2 & 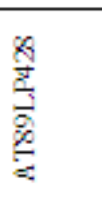 & $\begin{array}{c}\text { 4-Kbyte In-system Programmable Flash, } \\
\text { Single Cycle } 8051 \text { Microcontroller, } 512 \\
\text { Bytes Flash Data Memory, } 768 \text { Bytes } \\
\text { RAM, PWM, UART, SPI, I/O = up to } 30 \text {, } \\
\text { Analog Comparator, Internal RC Oscillator, } \\
\text { On-chip Debug }\end{array}$ \\
\hline 3 & 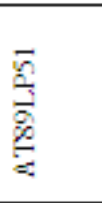 & $\begin{array}{l}\text { 4-Kbyte In-system Programmable Flash, } \\
\text { Single Cycle } 8051 \text { Microcontrollerwith } 12- \\
\text { clock Compatibility Mode, } 256 \text { Bytes Flash } \\
\text { Data Memory, } 256 \text { Bytes RAM, } 3 \text { Timers, } \\
\text { UART, WDT, I/O = up to } 36 \text {, Internal RC } \\
\text { Oscillator }\end{array}$ \\
\hline 4 & \begin{tabular}{l}
$\frac{9}{3}$ \\
$\frac{3}{2}$ \\
\hdashline
\end{tabular} & $\begin{array}{c}\text { 64-Kbyte In-5ystem Programmable Flash, } \\
\text { Single Cycle } 8051 \text { Microcontroller, } 8192 \\
\text { Bytes Flash Data Memory, } 4352 \text { Bytes } \\
\text { RAM, PWM, UART, TWI, SPI, I/O = up to } \\
\text { 38,10-bitAD, Internal RC Oscillator, On- } \\
\text { chip Debug }\end{array}$ \\
\hline 5 & $\frac{8}{8}$ & $\begin{array}{c}\text { 8-Kbyte In-system Programmable Flash, } \\
\text { Single Cycle } 8051 \text { Microcontroller, } 1024 \\
\text { Bytes Flash Data Memory, } 768 \text { Bytes } \\
\text { RAM, PWM, UART, SPI, I/O = up to } 30 \text {, } \\
\text { Analog Comparator, Internal RC Oscillator, } \\
\text { On-chip Debug }\end{array}$ \\
\hline 6 &  & $\begin{array}{l}\text { 2/4-Kbyte In-5ystem Flash, Single-Cycle } \\
\text { Microcontroller, } 256 \text { Bytes RAM, SPI, } \\
\text { PWM, } 20 \text { MIPS Throughput at } 20 \mathrm{MHz}\end{array}$ \\
\hline
\end{tabular}


Table 3: Atmel 8-bit Flash ISP (In-System Programmable) Family Members

\begin{tabular}{|c|c|c|}
\hline $\begin{array}{l}\text { S. } \\
\text { N. }\end{array}$ & Devices & Description \\
\hline 1 & AT 89C5115 & $\begin{array}{c}\text { Low-pin-count 8-bit } \\
\text { Microcontroller with A/D } \\
\text { Converter and 16K Bytes of Flash } \\
\text { Memory }\end{array}$ \\
\hline 2 & $\begin{array}{c}\text { AT } \\
\text { 89C51AC2 }\end{array}$ & $\begin{array}{l}\text { 8-bit microcontroller with 32Kbyte } \\
\text { Flash, 2KByte EEPROM and 10-bit } \\
\text { A/D converter }\end{array}$ \\
\hline 3 & AT89C51AC3 & $\begin{array}{l}\text { 8-bit microcontroller with A/D } \\
\text { converter and 64-Kbyte Flash. 2- } \\
\text { Kbyte RAM, 2-Kbyte EEPROM, } \\
\text { SPI. Power Fail Detect (no need for } \\
\text { external brown- out) Pin out } \\
\text { compatible with T89C51AC2 }\end{array}$ \\
\hline 4 & AT89C51ED2 & $\begin{array}{c}\text { High performance 8-bit } \\
\text { microcontroller 64 Kbytes Flash, } 2 \\
\text { Kbytes EEPROM } \\
\end{array}$ \\
\hline 5 & AT89C51IC2 & $\begin{array}{l}\text { AT89C51IC2 is a } 80 \mathrm{C} 518 \text {-bit } \\
\text { microcontrollers featuring a } 32 \mathrm{~K} \\
\text { bytes Flash code memory and a } \\
\text { two-wire interface (TWI) }\end{array}$ \\
\hline 6 & AT89C51ID2 & $\begin{array}{c}\text { High performance 8-bit } \\
\text { microcontroller } 64 \text { Kbytes Flash, } 2 \\
\text { Kbytes EEPROM and Two Wire } \\
\text { Interface (TWI) }\end{array}$ \\
\hline 7 & $\begin{array}{c}\text { AT89C51RB2 } \\
\text { /RC2 } \\
\text { /RD2 / RE2 }\end{array}$ & $\begin{array}{c}\text { High performance } 8 \text {-bit } \\
\text { Microcontroller } 16 / 32 / 64 / 128 \\
\text { Kbytes Flash }\end{array}$ \\
\hline 8 & AT89LS51/52 & $\begin{array}{c}\text { Low-Voltage Microcontroller with } \\
\text { 4K /8K Bytes In-System } \\
\text { Programmable Flash }\end{array}$ \\
\hline 9 & $\begin{array}{c}\text { AT89S2051 } \\
/ 4051\end{array}$ & $\begin{array}{c}\text { 2.7-Volt, 80C31 Microcontroller } \\
\text { with 2K/4K Bytes In-System } \\
\text { Programmable Flash, 20-pin } \\
\text { Package. }\end{array}$ \\
\hline 10 & AT89S51 /52 & $\begin{array}{c}\text { 8-bit Microcontroller with } 4 \mathrm{~K} / 8 \mathrm{~K} \\
\text { Bytes In-System Programmable } \\
\text { Flash }\end{array}$ \\
\hline 11 & AT89S8253 & $\begin{array}{l}\text { In-System Programmable } \\
\text { Microcontroller with } 12 \mathrm{~K} \text { bytes } \\
\text { Flash \& } 2 \mathrm{~K} \text { bytes EEPROM }\end{array}$ \\
\hline
\end{tabular}

Table 4: Atmel 8-bit Flash (Reprogrammable) Family Members

\begin{tabular}{|c|c|c|}
\hline S.N. & Devices & Description \\
\hline 1 & AT 89C2051 & $\begin{array}{c}\text { 2.7-Volt, 80C31 Microcontroller } \\
\text { with 2K bytes Flash, 20-Pin } \\
\text { Package }\end{array}$ \\
\hline 2 & AT 89C4051 & $\begin{array}{c}\text { 3Volt, 80C31 Microcontroller } \\
\text { with 4K bytes Flash, 20-Pin } \\
\text { Package }\end{array}$ \\
\hline 3 & AT 89C51RC & $\begin{array}{c}\text { 8-bit Microcontroller with 32K } \\
\text { Bytes Flash }\end{array}$ \\
\hline 4 & AT 89C55WD & $\begin{array}{c}\text { 80C32 Microcontroller with } \\
\text { 20K Bytes Flash }\end{array}$ \\
\hline
\end{tabular}

Table 5: Atmel 8-bit CAN Networking MCUs Family Members

\begin{tabular}{|c|c|c|}
\hline S.N. & Devices & Description \\
\hline 1 & AT & $\begin{array}{c}\text { 8-bit microcontroller with CAN } \\
\text { controller and 64-Kbyte Flash. 2- } \\
\text { Kbyte RAM, 2-Kbyte EEPROM, SPI. } \\
\text { Power Fail Detect (no need for } \\
\text { external brown- out). Pin out } \\
\text { compatible with T89C51CC01 }\end{array}$ \\
\hline 2 & ATC51CC03 & $\begin{array}{c}\text { 8-bit microcontroller with CAN } \\
\text { controller and 32-Kbyte Flash. 1.2- } \\
\text { Kbyte RAM, 2-Kbyte EEPROM. Pin } \\
\text { out compatible with T89C51CC01 }\end{array}$ \\
\hline 3 & 89C51CC01 & $\begin{array}{c}\text { Low pin count 8-bit microcontroller } \\
\text { with CAN controller and 16-Kbyte } \\
\text { Flash }\end{array}$ \\
\hline
\end{tabular}

Table 6: Atmel 8-bit USB MCUs Family Members

\begin{tabular}{|c|c|c|}
\hline S.N. & Devices & Description \\
\hline 1 & AT 83C5134 & $\begin{array}{c}\text { USB C51-based Microcontroller } \\
\text { with 8K Bytes ROM, } 1280 \text { bytes } \\
\text { RAM, Power Supply: } 2.7 \mathrm{~V} \text { to } 3.6 \mathrm{~V} \text {, } \\
\text { 6 USB Endpoints, TWI, SPI, } \\
\text { UART, PCA }\end{array}$ \\
\hline 2 & AT 83C5135 & $\begin{array}{c}\text { USB C51-based Microcontroller } \\
\text { with 16K Bytes ROM, } 1280 \text { bytes } \\
\text { RAM, Power Supply: } 2.7 \mathrm{~V} \text { to } 3.6 \mathrm{~V} \text {, } \\
6 \text { USB Endpoints, TWI, SPI, } \\
\text { UART, PCA }\end{array}$ \\
\hline 3 & AT 83C5136 & $\begin{array}{c}\text { USB C51-based Microcontroller } \\
\text { with 32K Bytes ROM, } 1280 \text { bytes } \\
\text { RAM, Power Supply: } 2.7 \mathrm{~V} \text { to } 3.6 \mathrm{~V} \text {, } \\
6 \text { USB Endpoints, TWI, SPI, } \\
\text { UART, PCA }\end{array}$ \\
\hline 4 & $\begin{array}{c}\text { AT } \\
\text { 89C5130A-M }\end{array}$ & $\begin{array}{c}\text { USB C51-based Microcontroller } \\
\text { with 16K Bytes Flash, 1K Byte } \\
\text { Data EEPROM, } 1280 \text { bytes RAM, } \\
\text { Extended Range Power Supply: } \\
\text { 2.7V to 5.5V, 7 USB Endpoints, } \\
\text { TWI, SPI, UART, PCA }\end{array}$ \\
\hline 5 & $\begin{array}{c}\text { AT } \\
\text { 89C5131A-L }\end{array}$ & $\begin{array}{l}\text { USB C51-based Microcontroller } \\
\text { with 32K Bytes Flash, 1K Byte } \\
\text { Data EEPROM, } 1280 \text { bytes RAM, } \\
\text { Low Voltage Range Power Supply: } \\
\text { 3.0V to 3.6V, 7 USB Endpoints, } \\
\text { TWI, SPI, UART, PCA. } \\
\text { Recommended device with } \\
\text { extended voltage range: } \\
\text { AT89C5131A-M (2.7-5.5V) }\end{array}$ \\
\hline 6 & $\begin{array}{c}\text { AT } \\
\text { 89C5131A-M }\end{array}$ & $\begin{array}{c}\text { USB C51-based Microcontroller } \\
\text { with 32K Bytes Flash, 1K Byte } \\
\text { Data EEPROM, } 1280 \text { bytes RAM, } \\
\text { Extended Range Power Supply: } \\
\text { 2.7V to 5.5V, } 7 \text { USB Endpoints, } \\
\text { TWI, SPI, UART, PCA }\end{array}$ \\
\hline 7 & AT 89C5132 & $\begin{array}{c}\text { USB C51-based Microcontroller } \\
\text { with 64K Bytes Flash, } 2304 \text { bytes } \\
\text { RAM, } 4 \text { USB Endpoints, SPI, } \\
\text { UART, IDE, TWI, Multi Media } \\
\text { Card, Data Flash, I2S, 10-bit ADC }\end{array}$ \\
\hline
\end{tabular}


Table 7: Atmel 8-bit Lighting MCUs Family Members

\begin{tabular}{|c|c|c|}
\hline S.N. & Devices & Description \\
\hline 1 & $\begin{array}{c}\text { AT } \\
\text { 83EB5114 }\end{array}$ & $\begin{array}{l}\text { Dedicated to lighting control } \\
\text { applications, the AT83EB5114 } \\
\text { retains all the features of the standard } \\
80 \text { C51 with } 4 \text { Kbytes ROM program } \\
\text { memory, } 256 \text { bytes RAM, } 256 \text { bytes } \\
\text { EEPROM, a 7-source, 4-level } \\
\text { interrupt system, an on chip oscillator } \\
\text { and two timers/counters. Analog } \\
\text { functions include a 10-bit, } 6 \text { channels } \\
\text { A/D converter and two optimized } \\
\text { PWM units }\end{array}$ \\
\hline 2 & $\begin{array}{c}\text { AT } \\
\text { 89EB5114 }\end{array}$ & $\begin{array}{l}\text { Dedicated to lighting control } \\
\text { applications, the AT89EB5114 is the } \\
\text { Flash version of the AT83EB5114 } \\
\text { available for development purpose }\end{array}$ \\
\hline
\end{tabular}

Table 8: Atmel 8-bit ROM less Family Members

\begin{tabular}{|c|c|c|}
\hline S.N. & Devices & Description \\
\hline 1 & AT & 80C51 High Performance 8-bit \\
80C51RD2 & Microcontroller \\
\hline
\end{tabular}

\subsection{Low-Power Considerations}

Low power operation is preferred in many dedicated applications and portable-measuring applications in the industrial, medical, consumer and automotive market. PIC 8-bit microcontrollers are optimized to meet stringent performance requirements in high performance, cost-effective applications and its production, unit wise, is the second largest in the world [14]. The low power application in PIC microcontrollers is popular in medical electronics products that the manufacturers of PIC microcontrollers needed to form a special forum called as "Medical Products Group" in 2007 to address the strong demand in the medical electronics market including the development of smarter and easier to use products. Similarly, many low power features are available in Atmel microcontrollers also, such as, in case of idle mode of AT80C51RD2 (Atmel- ROM less MCUs), the CPU is frozen while the peripherals and the interrupt system are still operating for power saving purpose. In the Power-down mode, the RAM is saved and all other functions are inoperative. Another recent Atmel microcontroller AT89C5130A/31A-M with USB connectivity and which is highly applicable for remote applications such as WSN based monitoring as seen in subsection 5.1 .

It is obvious that the power dissipated by a CMOS device such as a PIC chip is proportional to the clock rate, i.e. more the clock rate more is the power dissipation. Hence one needs to optimize the clock rate for the design under consideration, such as temperature control using PIC microcontroller. The response time of the temperature sensor is more than a few hundred milliseconds and hence a few $\mathrm{kHz}$ clock will serve the purpose. The $32 \mathrm{kHz}$ crystal oscillator when used with a low-power version of a PIC part, such as the PIC 16LC74A, produces the very low supply current specification of $22.5 \mu \mathrm{A}$ (typical) and $48 \mu \mathrm{A}$ (max). Loading of the output pins needs to be avoided or minimized [8].

In practice, the PIC chip is intended to drive selected output pins and to use internal features. However, if outputs drive highimpedance CMOS inputs and if they are changed at a rate that is low relative to the PIC's clock rate, then the effect on PIC supply current is minimal. Likewise, if the internal analog-to-digital converter is used once per second (considering slow variations of the analog inputs), then one can bring down the requirement of the supply current than continuous ON status of the internal ADC [8].Such features are mostly useful in remote WSN applications where only one of the sensors needs to remain active for particular period.

Sleep mode is an important mode of the PIC family in which oscillator is halted, stopping all operations within the chip excluding watchdog timer and Timer1, if used with an external oscillator. One of these is kept running to awaken the PIC periodically [8]. This feature is mostly expected in WSN applications.

Table 9 shows PIC specifications for supply current under various conditions [8]. Though PIC 16LC74A is the most important family part considering industrial and dedicated applications; the other parts are almost similar in their low-power specifications. For example, the PIC16LC62A with clock speed of $32 \mathrm{kHz}$ draws the same $22.5 \mu \mathrm{A}$ (typical) and $48 \mu \mathrm{A}$ (max). These features hold well in case of WSN, an application in which life span of Battery is important.

Table 9: Supply Current for PIC16LC74A

\begin{tabular}{|c|c|c|c|}
\hline \multicolumn{2}{|c|}{ Operating conditions } & $\begin{array}{c}\text { Typical } \\
\text { current }\end{array}$ & $\begin{array}{c}\text { Maximum } \\
\text { current }\end{array}$ \\
\hline $\begin{array}{c}\text { Operation with } \\
\text { outputs } \\
\text { and optional } \\
\text { internal } \\
\text { resources } \\
\text { disabled }\end{array}$ & OSC $=4 \mathrm{MHz}$ & $2000 \mu \mathrm{A}$ & $3800 \mu \mathrm{A}$ \\
\cline { 2 - 4 } & OSC $=32 \mathrm{kHz}$ & $22.5 \mu \mathrm{A}$ & $48 \mu \mathrm{A}$ \\
\hline \multirow{2}{*}{ SLEEP mode } & $\begin{array}{c}\text { With WDT } \\
\text { disabled and } \\
\text { external } \\
\text { oscillator of } \\
\text { Timerl is } \\
\text { disabled }\end{array}$ & $0.9 \mu \mathrm{A}$ & $5 \mu \mathrm{A}$ \\
\cline { 2 - 4 } & $\begin{array}{c}\text { With WDT } \\
\text { enabled }\end{array}$ & $7.5 \mu \mathrm{A}$ & $30 \mu \mathrm{A}$ \\
\cline { 2 - 4 } & $\begin{array}{c}\text { With external } \\
\text { oscillator of } \\
\text { Timerl is } \\
\text { enabled }\end{array}$ & $\approx 21 \mu \mathrm{A}$ & $\approx 26 \mu \mathrm{A}$ \\
\hline A/D converter & $\begin{array}{c}\text { Enabled but not } \\
\text { converting }\end{array}$ & $90 \mu \mathrm{A}$ & --- \\
\hline
\end{tabular}

\subsection{Other Important features of PIC 8-bit Microcontrollers}

The various PIC package alternatives are available including low end $18 / 20$ - pin parts and some other important features like PWM, WDT, Serial I/O and Source and Sink current per I/O. Such low end options are very suitable for low power and low cost solutions such as electronic toys, robotic applications, robot drives, WSN, hand held automated tools, electronic gadgets, PC interfacing devices, spy cameras, security devices, surveillance devices and many more. Many devices such as PIC 16C71, PIC16C72, PIC 16C73A and PIC 16C74A provide ADC options from 4 to 8 channels though pin count is low [8]. 


\section{EXPERIMENTAL OBSERVATIONS}

Some timing simulation case studies are examined. Few of them are given below.

\subsection{Case study 1}

Simulation process to implement logic control for micro-processes so as to have quality product is done. Such logic control finds applications in Bio-technological, Tissue Culture, Chemical, Petrochemical or Pharmaceutical industries to control micro processes. Timing simulation analysis for easily available microcontroller 8051 / 89C51 was done on EdSim software. As depicted in fig.8, the logic control process took average time of 1.11 microseconds per instruction with the maximum clock rate of $12 \mathrm{MHz}$, or $11.1 \mu \mathrm{s}$ time for one iteration of 10 instructions. However, for specific chemical process to complete, it may need around more than $1,00,000$ such iterations. Thus this will take around $1,11,000 \mu \mathrm{s}$ time for $1,00,000$ iterations. The same process is done with PIC microcontroller (MP LAB) simulator which took only $1.8 \mu \mathrm{s}$ for one iteration or $18000 \mu \mathrm{s}$ for $1,00,000$ iterations. The conclusion is that PIC is able to give logic control operation with desired high speed and accuracy as expected in such specific chemical processes. Hence, one should prefer PIC microcontroller in such processes due to accurate and speedier logic control of the chemical processes to have quality product. The selection of the PIC Microcontroller can be done from PIC part numbers given in subsection 5.1 depending on the need of program memory, power requirements, ADC Channels and number of I/O devices. However, for slow chemical processes, authors suggest that one may prefer the most popular microcontroller in the industry $8051 / 89 \mathrm{C} 51$ as the design expertise is easily available.

\subsection{Case study 2}

Simulation process to implement I/O operation for display control devices is done using EdSim software, as depicted in fig. 9. Such ALPs are used in displaying alpha-numeric characters in a particular sequence. Actual display control starts from the second instruction which moves hexadecimal data 24 h (i.e. 00100100 in binary) into the accumulator and then transferred to port 1 (p1) of $89 \mathrm{c} 51$ microcontroller. ON-OFF status of the seven segment display is controlled by the bit pattern in the accumulator. In fact, the port pins are connected to the 7 segment LEDs. This way, different alpha-numeric characters are displayed using various hex codes routed through accumulator, such as $79 \mathrm{~h}, 24 \mathrm{~h}, 30 \mathrm{~h}$, $19 \mathrm{~h}, 12 \mathrm{~h}, 03 \mathrm{~h}, 78 \mathrm{~h}, 00 \mathrm{~h}$ and $16 \mathrm{~h}$ as given in the every alternate statement of the ALP given below. The sequence is repeated for few times for continuous display. Commercially, huge alphanumeric characters are continuously displayed. The ALP given below is a simple representation of such huge programs. It is again seen that the process takes $221 \mu$ s for 215 instructions, i.e. on an average $1 \mu \mathrm{s}$ per instruction. In case of case study 1 , PIC has given better performance in terms of speed. However, in display operation the basis of performance is persistence of vision which is only $1 / 16$ of the second. Hence, authors recommend that for such operations 8051 /89C51 should be preferred. Simulation results for few processes are given in the conclusion.

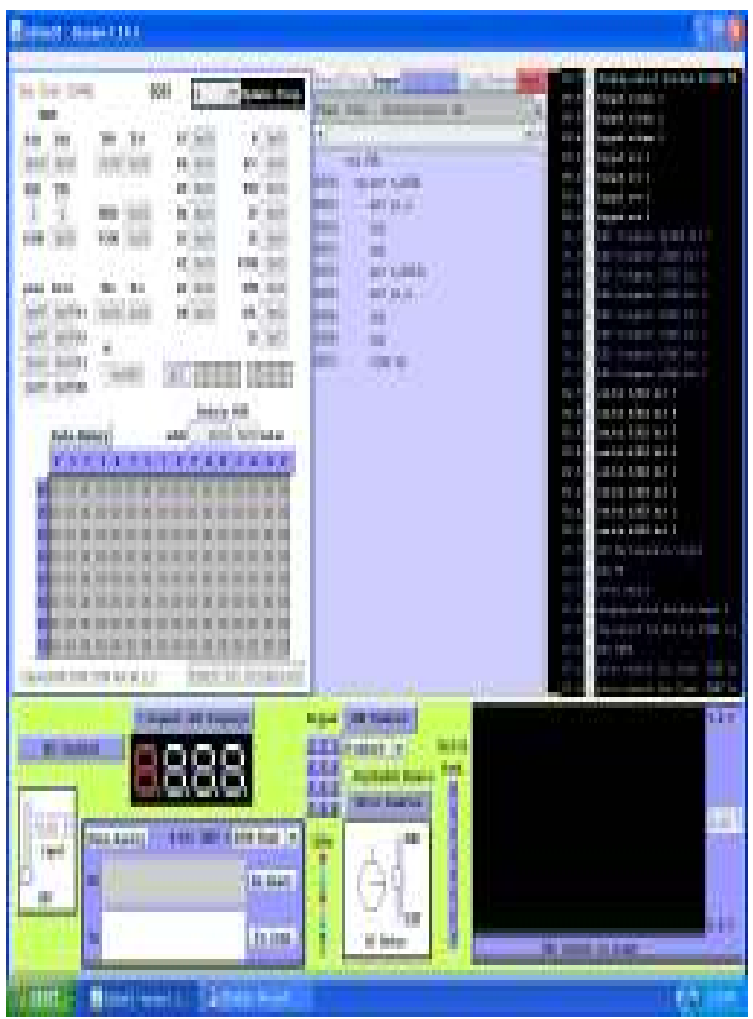

Fig. 8 Timing simulation of iterative logic control: Iterative execution of the program takes $53 \mu \mathrm{s}$



Fig. 9 Timing simulation process to implement I/O operation for display control devices 


\subsection{Timing simulation analysis in nutshell}

Simulation for number of iteration is carried out for various family members and the execution time taken is shown in fig. 10(a) to fig. 10(d) for different clock frequencies. It is seen that PIC microcontrollers take very less execution time than Atmel parts at the same clock frequency. It is due to instruction set of PIC. Almost all the instructions of PIC take single clock cycle to execute. Hence, for the same task, PIC microcontroller takes almost $1 / 10^{\text {th }}$ time for execution of iterative programs. PICs are thus very helpful when one micro-process consists of so many iterative programs to execute.



Fig. 10(a) Comparison of timing simulation analysis for 1 to 6 iterations at $12 \mathrm{MHz}$

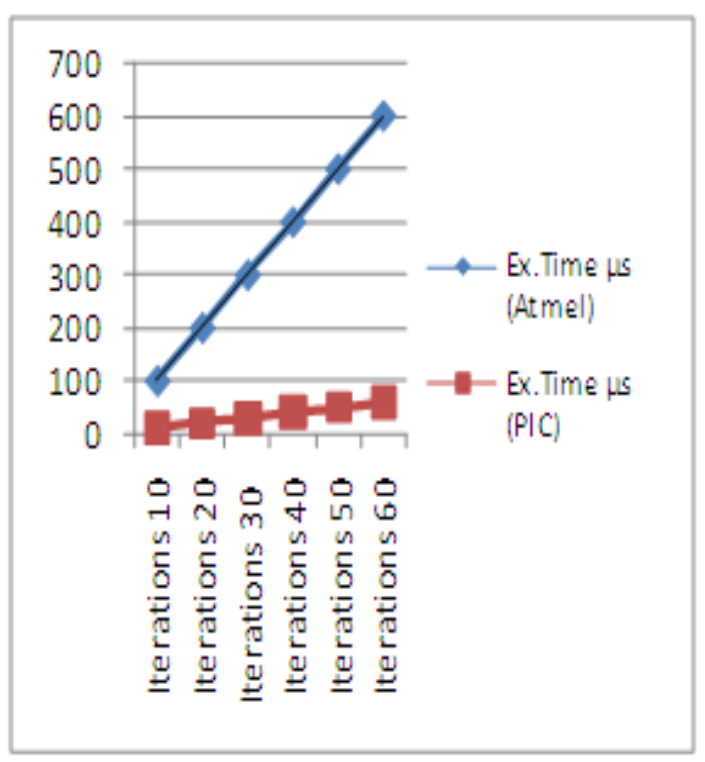

Fig. 10(b) Comparison of timing simulation analysis for 10 to 60 iterations at $12 \mathrm{MHz}$

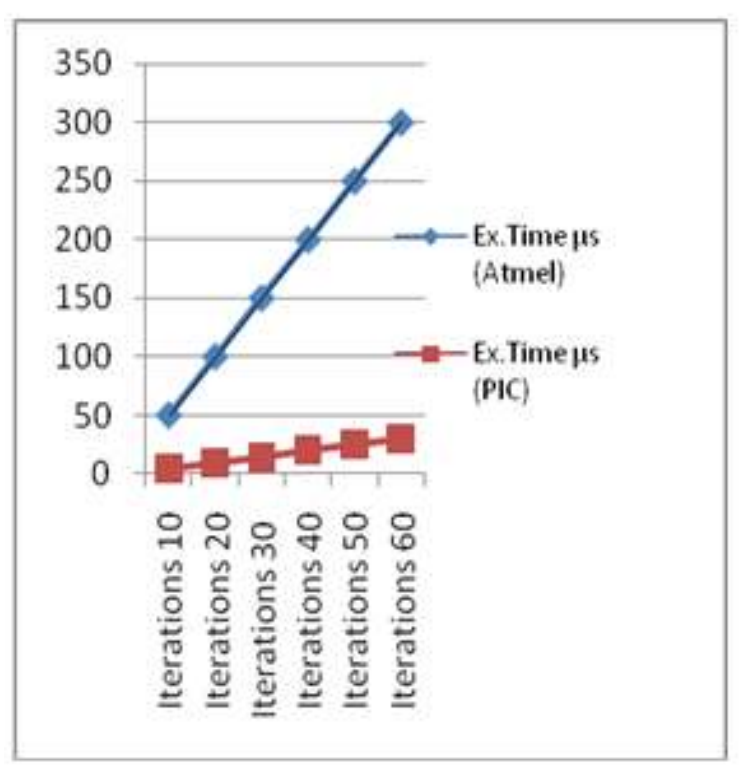

Fig. 10(c) Comparison of timing simulation analysis for 10 to 60 iterations at $24 \mathrm{MHz}$

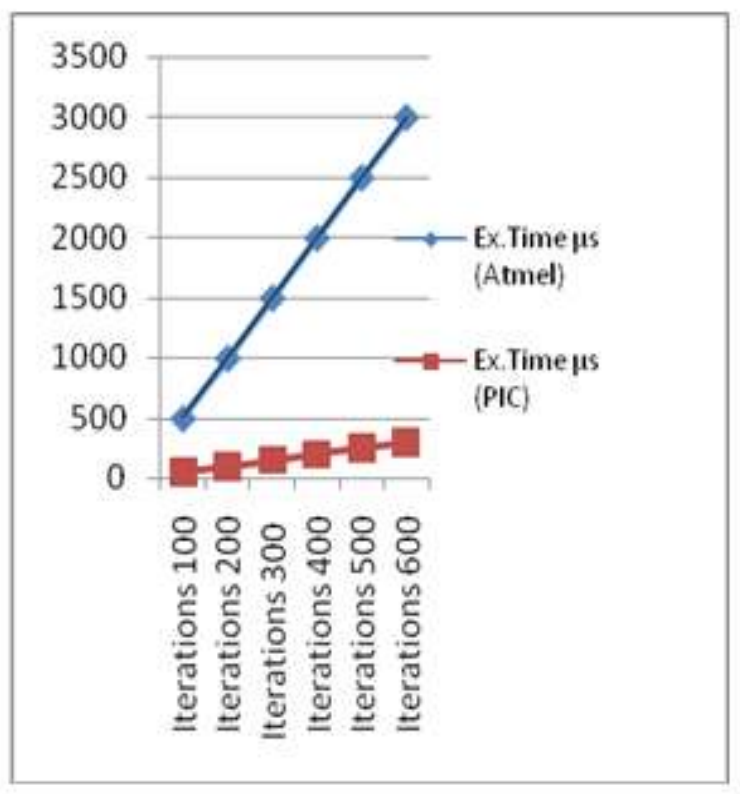

Fig. 10(d) Comparison of timing simulation analysis for 100 to 600 iterations at $24 \mathrm{MHz}$

\section{CONCLUSIONS}

In nutshell, tables 12 (A) gives the simulation results after executing application programs for the applications listed. Table 12 (B) gives the outcome based on detailed literature survey to enable the selection of the particular microcontroller for specific industrial applications. The conclusive information in table 12(A) and table 12 (B) is the readily available source for the first generation entrepreneurs and owners of small scale industries in the developing countries. 
Table 12(A): Consolidated results and conclusions based on simulation results

\begin{tabular}{|c|c|c|c|}
\hline $\begin{array}{l}\text { Name of the } \\
\text { Process } \\
\text { / Application }\end{array}$ & $\begin{array}{c}\text { Timing } \\
\text { Analysis } \\
\text { Results for } \\
8051 / \\
89 \text { C51 } \\
\end{array}$ & $\begin{array}{l}\text { Timing } \\
\text { Analysis } \\
\text { Results } \\
\text { for PIC }\end{array}$ & Conclusion \\
\hline $\begin{array}{c}\text { Bio- } \\
\text { technological }\end{array}$ & $\begin{array}{l}\text { Slow as the } \\
\text { execution time } \\
\text { needed is more } \\
\text { as compared to } \\
\text { the time needed } \\
\text { to control the } \\
\text { micro steps in } \\
\text { the process. }\end{array}$ & $\begin{array}{l}\text { Speedier } \\
\text { /Fast }\end{array}$ & $\begin{array}{l}\text { Accurate timing } \\
\text { control possible } \\
\text { due to PIC } \\
\text { controllers as } \\
\text { execution time } \\
\text { needed is less } \\
\text { even for } \\
\text { multiple } \\
\text { iteration as } \\
\text { compared to } \\
\text { 8051/89C51. } \\
\text { Hence PIC is } \\
\text { preferred. }\end{array}$ \\
\hline Tissue Culture & --do-- & $\begin{array}{l}\text { Speedier } \\
\text { /Fast }\end{array}$ & ---do-- \\
\hline Chemical & --do-- & $\begin{array}{l}\text { Speedier } \\
\text { /Fast }\end{array}$ & --do-- \\
\hline Petrochemical & --do-- & $\begin{array}{l}\text { Speedier } \\
\text { /Fast }\end{array}$ & --do-- \\
\hline Pharmaceutical & --do-- & $\begin{array}{l}\text { Speedier } \\
\text { /Fast }\end{array}$ & -- do- \\
\hline $\begin{array}{l}\text { Display } \\
\text { Control }\end{array}$ & $\begin{array}{l}\text { Better as slow } \\
\text { execution does } \\
\text { not affect the } \\
\text { principle of } \\
\text { persistence of } \\
\text { vision usually } \\
\text { needed in } \\
\text { Display control }\end{array}$ & $\begin{array}{l}\text { Speedier } \\
\text { /Fast }\end{array}$ & $\begin{array}{l}8051 / 89 \mathrm{C} 51 \text { is } \\
\text { preferred as the } \\
\text { basis of operation } \\
\text { is persistence of } \\
\text { vision in most of } \\
\text { the display } \\
\text { operation. }\end{array}$ \\
\hline $\begin{array}{c}\text { Domestic } \\
\text { Product } \\
\text { (Microwave } \\
\text { oven/ Washing } \\
\text { Machine) }\end{array}$ & $\begin{array}{l}\text { Better ON-OFF } \\
\text { control }\end{array}$ & $\begin{array}{c}\text { Best } \\
\text { ON-OFF } \\
\text { control }\end{array}$ & $\begin{array}{l}\text { Both can be } \\
\text { used.PIC preferred } \\
\text { due to on chip } \\
\text { ADCs available. }\end{array}$ \\
\hline $\begin{array}{c}\text { WSN } \\
\text { Applications }\end{array}$ & Slow & $\begin{array}{l}\text { Speedier } \\
\text { /Fast }\end{array}$ & $\begin{array}{l}\text { PIC is } \\
\text { recommended due } \\
\text { to on chip } \\
\text { ADCs, USART } \\
\text { available }\end{array}$ \\
\hline $\begin{array}{c}\text { Electronic } \\
\text { Digital Clock }\end{array}$ & Better & $\begin{array}{l}\text { Speedier } \\
\text { /Fast }\end{array}$ & $\begin{array}{l}8051 / 89 \mathrm{C} 51 \text { is } \\
\text { preferred as the } \\
\text { basis of operation } \\
\text { as the basis of } \\
\text { operation doesn't } \\
\text { warrant speedier } \\
\text { operation. }\end{array}$ \\
\hline
\end{tabular}

\begin{tabular}{|c|l|l|l|}
\hline $\begin{array}{c}\text { Electronics } \\
\text { Toys }\end{array}$ & Slow & Fast & $\begin{array}{l}\text { PIC is } \\
\text { recommended due } \\
\text { to on chip } \\
\text { ADCs, USART } \\
\text { available }\end{array}$ \\
\hline SCADA & Better & Fast & $\begin{array}{l}\text { PIC is } \\
\text { recommended due } \\
\text { to on chip ADCs, } \\
\text { USART available }\end{array}$ \\
\hline
\end{tabular}

Table 12 (B): Consolidated results based on detailed literature survey and application area

\begin{tabular}{|c|c|c|c|}
\hline 离 &  & Special Features & Application area \\
\hline 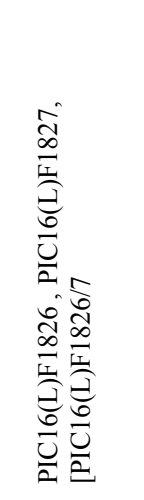 & 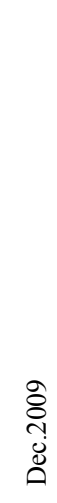 & $\begin{array}{l}\text { Enhanced Mid- } \\
\text { range core, 18- } \\
\text { Pin,mTouch } \\
\text { capacitive touch } \\
\text { sensing, extreme } \\
\text { low power } \\
\text { technology,12 } \\
\text { Channel 10b ADC } \\
\text { with Voltage } \\
\text { Reference, In } \\
\text { Circuit Serial } \\
\text { Programming } \\
\text { (ICSP),Extended } \\
\text { Watchdog Timer } \\
\text { (EWDT) }\end{array}$ & $\begin{array}{l}\text { Very low power } \\
\text { applications such as } \\
\text { remote SCADA, } \\
\text { WSN in hostile } \\
\text { environment. }\end{array}$ \\
\hline 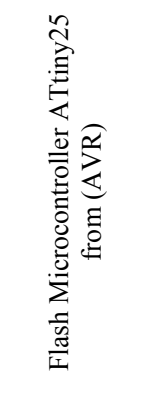 & 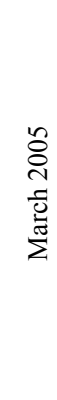 & $\begin{array}{l}\text { Flash, EEPROM } \\
\text { and SRAM } \\
\text { combinations, } \\
2 \text { KB of Self- } \\
\text { Programmable } \\
\text { Flash memory, }\end{array}$ & $\begin{array}{l}\text { i) Targeting battery } \\
\text { chargers, sensor } \\
\text { endpoints and low- } \\
\text { end motor control } \\
\text { applications. } \\
\text { ii) Temperature } \\
\text { calibration of system } \\
\text { parameters using } \\
\text { internal temperature } \\
\text { sensor. } \\
\text { iii) To monitor and }\end{array}$ \\
\hline 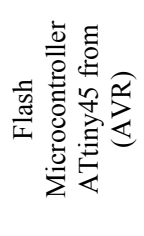 & 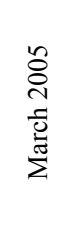 & $\begin{array}{l}\text { Flash, EEPROM } \\
\text { and SRAM } \\
\text { combinations, } \\
4 \text { KB of Self- } \\
\text { Programmable } \\
\text { Flash memory, }\end{array}$ & $\begin{array}{l}\text { power supply voltages } \\
\text { and currents and } \\
\text { communicate to the } \\
\text { system host through } \\
\text { its Universal Serial } \\
\text { Interface (USI) } \\
\text { communication }\end{array}$ \\
\hline 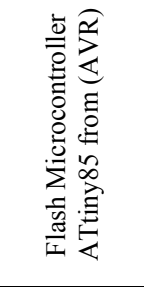 & 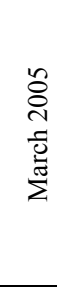 & $\begin{array}{l}\text { Flash, EEPROM } \\
\text { and SRAM } \\
\text { combinations, } \\
8 \text { KB of Self- } \\
\text { Programmable } \\
\text { Flash memory }\end{array}$ & $\begin{array}{l}\text { iv) The on-chip, low } \\
\text { power PLL is used to } \\
\text { control two Pulse } \\
\text { Width Modulation } \\
\text { capable of generating } \\
\text { a } 250 \mathrm{kHz} \text { PWM } \\
\text { output at } 8 \text {-bit } \\
\text { resolution. }\end{array}$ \\
\hline
\end{tabular}




\begin{tabular}{|c|c|c|c|c|}
\hline  & 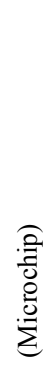 & $\begin{array}{l}\hat{8} \\
\text { ते } \\
\dot{\Xi}\end{array}$ & $\begin{array}{l}200 \text { MIPS, } 27 \text { DMA } \\
\text { channels, including } \\
\text { 18-channel DMA } \\
\text { controller, on-chip } \\
\text { data transfer rates } \\
\text { up to } 41.6 \text { Gbps, } 02 \\
\text { external bus } \\
\text { interfaces (EBIs) } \\
\text { support, gigabyte- } \\
\text { plus external } \\
\text { memories }\end{array}$ & $\begin{array}{l}\text { Suited for graphically } \\
\text { interfaced, data- } \\
\text { intensive applications. }\end{array}$ \\
\hline 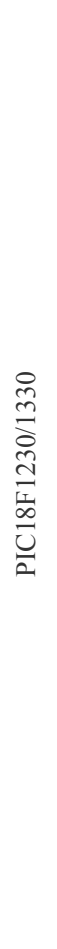 & 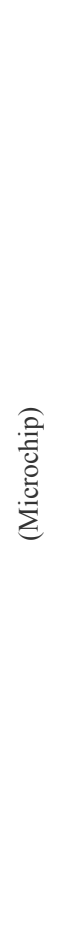 & 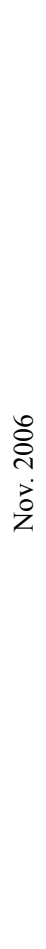 & $\begin{array}{l}\text { 14-bit,3-phase } \\
\text { PWM module with } \\
\text { edge or center- } \\
\text { aligned operation, } \\
\text { override logic for } \\
\text { special } \\
\text { commutation } \\
\text { functions, } \\
\text { programmable } \\
\text { dead-band delay, } \\
\text { fault inputs for } \\
\text { hardware shutdown, } \\
\text { output override } \\
\text { functions and up to } \\
3 \text { channels of } \\
\text { complimentary } \\
\text { outputs. Automotive } \\
\text { appliances such as } \\
\text { door and window } \\
\text { lifts, mirrors, } \\
\text { sunroofs, anti-pinch } \\
\text { windows, garage- } \\
\text { door openers, } \\
\text { throttle control, } \\
\text { smart fan } \\
\text { controllers, } \\
\text { windshield wipers, } \\
\text { power seats. }\end{array}$ & $\begin{array}{l}\text { i) Provides electronic } \\
\text { motor control of 3- } \\
\text { phase motors, brushed } \\
\text { DC motors and } \\
\text { stepper motors in } \\
\text { washers, dryers, } \\
\text { refrigerators, vacuum } \\
\text { cleaner. } \\
\text { ii)Commercial } \\
\text { applications such as } \\
\text { low-end UPS, switch- } \\
\text { mode power supplies, } \\
\text { arena lighting, fiber- } \\
\text { optic routing, power- } \\
\text { bridge drivers, fuel } \\
\text { pumps, DC-DC } \\
\text { converters, smart fan } \\
\text { controllers. } \\
\text { iii)Automotive } \\
\text { appliances such as } \\
\text { door and window lifts, } \\
\text { mirrors, sunroofs, } \\
\text { anti-pinch windows, } \\
\text { garage-door openers, } \\
\text { throttle control, smart } \\
\text { fan controllers, } \\
\text { windshield wipers, } \\
\text { power seats. }\end{array}$ \\
\hline 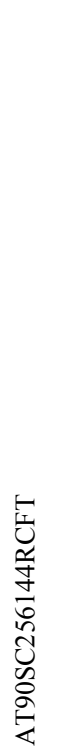 & 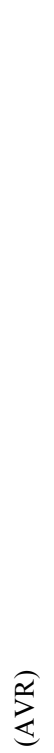 & 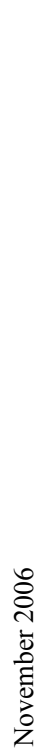 & $\begin{array}{l}\text { Dual-interface } \\
\text { contact and } \\
\text { contactless smart } \\
\text { card chip, large } \\
\text { EEPROM } \\
\text { nonvolatile memory } \\
\text { provides sufficient } \\
\text { capacity to allow } \\
\text { large data storage } \\
\text { such as ten fingertip } \\
\text { images of the } \\
\text { passport holder } \\
\text { (around 10 } \\
\text { Kbytes/image), } \\
\text { leaving enough } \\
\text { space for other data } \\
\text { (photo holder, } \\
\text { encryption keys) } \\
\text { etc, extremely fast } \\
\text { extended on-chip } \\
\text { tuning capacitance } \\
\text { options. }\end{array}$ & $\begin{array}{l}\text { i) High-end electronic } \\
\text { identity markets, } \\
\text { compliant with new } \\
\text { specifications for e- } \\
\text { passport of } \\
\text { International Civil } \\
\text { Aviation Organization } \\
\text { (ICAO). } \\
\text { ii) The ROM and } \\
\text { RAM sizes, combined } \\
\text { with the computing } \\
\text { power of the } \\
\text { secureAVR } \\
\text { architecture, make this } \\
\text { chip perfectly suited } \\
\text { for java card } \\
\text { implementations. } \\
\text { iii) It can cope up with } \\
\text { different antenna } \\
\text { technologies due to } \\
\text { tuning capacitance } \\
\text { options . }\end{array}$ \\
\hline
\end{tabular}

\section{ACKNOWLEDGEMENTS}

Authors are sincerely thankful to Mr. P. P. Ambekar (Managing Director, Ambekar Associates- VLSI and Embedded Solutions, Aurangabad, Maharashtra, India) for permission to conduct the timing simulation analysis for different 8-bit microcontrollers at his industry.

\section{REFERENCES}

[1] I.F. Akyildiz, S.Weilian, et al., "A Survey on Sensor Networks," IEEE Communications Magazine, vol. 40, no. 8, 2002.

[2] C. Chong and S.P. Kumar, "Sensor Networks: Evolution, Opportunities, and Challenges," Proc. IEEE, vol. 91, no. 8, 2003.

[3] D. Culler, D. Estrin, and M. Srivastava, "Overview of Sensor Networks,” IEEE Computer, vol. 37, no. 8, 2004.

[4] S.R. Madden, M.J. Franklin, and J.M. Hellerstein, and W. Hong, "Tinydb: An Acquisitional Query Processing System for Sensor Networks," ACM Trans. Database Systems, vol. 30, no. 1, 2005.

[5] Chih-Chieh Han et al., "A Dynamic Operating System for Sensor Nodes," Proceedings of International Conference on Mobile Systems, Applications, and Services (MobiSys 05), ACM Press, 2005.

[6] John B. Peatman, Design with PIC Microcontrollers, eighth reprint, Pearson Education, 2004, p.p. 212 - 224.

[7] NASDAQ: MCHP, "Microchip Technology Announces Net Sales and Net Income for Third Quarter Fiscal Year 2007 and Record Quarterly Cash Dividend," Microchip Financial Press Release, Arizona, p.p.1- 6, Thomas Publishing Company, January 31, 2007.

[8] Databook on current PIC Microcontroller Family Product, 2004. p.p. 12 and Databook on 8- bit AVR Microcontroller with 8-k bytes in-System Programmable Flash, 2006. p.p.07 -24 .

[9] Dhananjay V. Gadre, Programming and Customizing the AVR Microcontroller Design with PIC Microcontrollers, second reprint, TMH, 2004, p.p. 21 - 58. 